Sección General

\title{
Sociological Study of Identity Instability in Children of Parents with Drug Addiction
}

Estudio sociológico de la inestabilidad de identidad en hijos de padres con drogadicción

\author{
Zohreh Najafi Asl | University of Tehran - IRAN | \\ Corresponding Author. Department of Welfare and Planning, Faculty of Social Sciences, University Tehran, Tehran, Iran. Mailing Address: Next to Shariati Hospital, \\ Jalal Al Ahmad Highway, Tehran, Iran, Cellphone: +98-912- 115-0733. E-mail: najafiasl@ut.ac.ir \\ Somayeh Haghi | Minin Nizhny Novgorod State Pedagogical University - RUSSIA | \\ PhD Candidate of Rural Sociology, Faculty of Social Sciences, University Tehran, Tehran, Iran. E-mail: s.haghi@ut.ac.ir
}

\begin{abstract}
Addiction usually finds its way into the family by the father or husband and is consolidated in the family when other members, the mother and the children, become addicted as well. In this situation, children's vulnerability imposes unrecoverable consequences on the family. One of these undesirable impacts is the children's identity instability. The present research has conducted a sociological study of identity instability in children of parents with drug addiction.
\end{abstract}

Keywords: Drug addiction, Family, addiction, Identity instability, Annihilation of self-confidence

RESUMEN: La adicción por lo general encuentra su camino en la familia por el padre o esposo y se consolida en la familia cuando otros miembros, la madre y los hijos, también se vuelven adictos. En esta situación, la vulnerabilidad de los niños impone consecuencias irrecuperables en la familia. Uno de estos impactos indeseables es la inestabilidad de la identidad de los niños. La presente investigación ha realizado un estudio sociológico de la inestabilidad de la identidad en hijos de padres con adicción a las drogas.

Palabras clave: adicción a las drogas, familia, adicción, inestabilidad de la identidad, aniquilación de la autoconfianza. 


\section{INTRODUCTION}

The contemporary society is engaged with the problem of continuous expansion of drug addiction in the country and an increase in the rate of addicted women and young people. The tendency to drug addiction is formed under the influence of various factors, one of which is the family environment. Literature suggests that family variables have expansive, deep effects on this social phenomenon and addiction's deep penetration in families is consolidated through the consistency of its damages on the institution of the family. In other words, addiction imposes a potential pressure on the family that can have undesirable impacts on the members (Mahboubimanesh, 2003:6).

In this situation, children are stuck in an unfavorable environment, which is unhealthy according to the absolute health standards. Furthermore, they realize their unstable, uncertain status when they compare their situation with other children. In families with addicted parents, (Malekpour et al, 2012: 231) the position of family members is not confirmed and parents do not enjoy much respect (Ghorbani et al, 2014: 47). Consequently, conflict and violence are heightened between the family members and the family will ultimately turn into a damaging institution (Aghabakhshi,1996: 48-72; Mohammadifar, 2013: 37).

Therefore, it could be argued that, due to drug addiction, parents are unable to respond to their children's needs, such as looking over, guiding, and educating them, teaching them about discipline, and their age-specific needs (Jazayeri,2002: 17). As a result, children's physical, affectional, and behavioral problems are increased and issues such as depression, low self-esteem, and anxiety emerge that will ultimately lead into appalling educational status, communicational problems, and isolation (Shafiei, 2013: 146). In this sense, the children of addicted parents suffer a low life quality in all aspects of their lives. The quality-of-life index for children of addicted parents, based on gender, type of drugs, and number of family members, indicates that, under addiction in the family, quality of life is severely deteriorated and, ultimately, the children's vulnerability is increased (Narimani, 2014: 117-118). In this situation, children suffer from issues such as mental-psychological complications, anxiety, depression, disappointment, despair, and tendency to criminal activities. Therefore, it could be certainly claimed that children with addicted parents are one of the most vulnerable groups in the society (Narimani, 2014: 108).

Drug addiction is generally a personality complication. It is one of the fruitless sorts of adjustment in life, which individuals with particular personality tendencies may choose where there are suitable access and social-cultural facility. Therefore, it could be argued that part of the psychological explanation of drug addiction is a hypothetical addict who is itself an outcome of problematic relations in the family, improper reinforcements, the absence of a healthy role model, parents' complicated expectations, and absence of love and respect. Psychologically and according to the initial level or the principle of pleasure, an immature personality dependent on drugs is after pleasure and satisfaction and expects using drugs to reinforce its behavior.

Furthermore, according to Gold, the individuals' cognitive status is considered as a focal point that identifies the move from entertaining drug use toward complete addiction. According to this theory, in the addiction process, simulation is important as an encouraging factor. Individuals with problems who are incapable of responding to the society's expectations and needs encounter conflicts that are manifested in the form of anxiety. Anxiety is a general feeling that many of us experience in various degrees (Abadinsky, 2005).

Addicts, however, are those who interpret their anxiety as incapability in controlling themselves and their surrounding environment. They feel that they are powerless in changing the status and overcoming the tensions. The most important cognitive flaw in addicts is that there is no possible way to compromise with factors that create tensions (Ahmadi, 2016). Under such approach, addicts live in a critical condition where they are unable of making decisions. They are incapable of achieving high human goals or even to play their own roles in life.

Therefore, it could be concluded that considering the importance of psychological and social factors in the annihilation of children's identity due to parents' drug addiction, the present study has more strongly sought the role of social factors to analyze the phenomenon through a sociological approach. 


\section{METHODOLOGY}

The study's methodology, considering the novelty of the subject and the absence of much literature on the issue (Azkia at al, 2011: 21), is qualitative, using the grounded theory. Accordingly, data is produced in the research field and through techniques such as semi-structured interviews, recording the observations, and note-taking. In this methodology, the data gathered in the field cross three analytical stages of open coding, axial coding, and selective coding to turn into meaningful information.

Participants: In qualitative studies, unlike in the quantitative studies, people are selected due to their information, experience, or idea about the subject of the research. The present study utilized the purposive sampling method. In this sampling method, people are selected due to their information, experience, or idea about the subject of the research. Therefore, families (residing in Tehran) were chosen, in which the father, the mother, or any other member had complications or a history of drug addiction. Selecting the participants continued until the researchers reached a theoretical saturation and the interviews did not add any new information to the study. The probability of theoretical saturation threshold for the present study was considered to be at 40 participants (Najafi Asl, 2015: 55).

\section{RESEARCH FINDINGS}

The required data were gathered through interviews with participants and were later analyzed. Those issues of the interviews with children during the open coding and axial coding stages were extracted: Contexts for the start of drug addiction, Psychological and affectional impacts on the child, displaying a normal life, Violence against the child, General impacts on the child, being expelled from the society, Parents' irresponsibility about the child, Child's efforts to revive the life, Child's efforts to rebuild the future.

Finally, by analyzing the above-mentioned concepts and issues, the final model of the research was extracted in the selective coding stage. Table 1 illustrates the final model and the research findings.

\section{Table 1. Final Research Model}
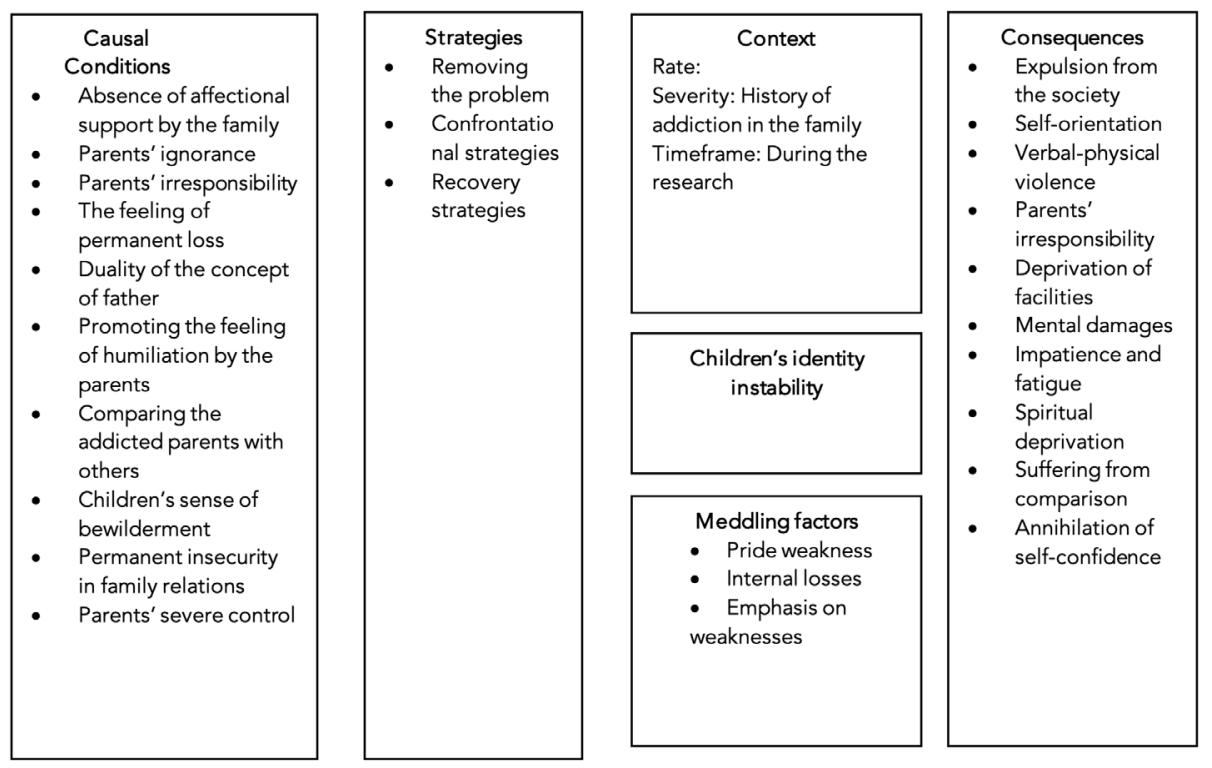

Considering the final model, the aspects of the model are analyzed in detail.

\section{a) Causal factors effective on the emergence of identity instability in children}

The absence of affectional support of the family, which is particularly seen by the addicted parents concerning their children, creates an environment empty of affection for the children. Addicted parents, because of characteristics such as self-orientation and isolationism whose only goal is to focus on preparing and using drugs, ignore their children. The ignorance is more severe and the feeling of affectional deprivation is deeper when 
addiction is stronger, longer, and more natural and this leads to parents' irresponsibility toward their children. A participant says, "He never thought about school because he was always using. He only came once. When my father was there, now he isn't. he's in prison. He only asks sometimes on the phone because there's no one else" (Child of an addict, 9 years old).

Losses experienced by the children due to their parents' addiction, especially the father's, create a permanent sense of loss in them and have unrecoverable psychological and social consequences. Because of these deep losses, children are extremely in search of an affectional support. However, parents' addiction, especially the father's, creates a severe affectional repulsion in father-child relations along with the affectional attraction that will finally lead to a sense of duality in the concept of a father for the child.

Addicted parents accept their addiction after a time and consider it part of the everyday life. They require the others to accompany them but a feeling of complete incapability surrounds them. Accordingly, addicted parents, especially the father, try to cover up their disabilities and transform a sense of incapability and humiliation to their children in response to their objections. When the children compare their addicted parents with others under the context of affectional deprivation, the comparison outlines the differences between addicted and healthy parents. A participant says, "When my father wasn't healthy, he ignored us. Their fathers came to school with a lot of food. They gave it to their children. There I felt sad" (Child of an addict, 10 years old).

Children's sense of bewilderment is, in fact, their confusion about their family's unstable status. This is a result of a condition where the children feel insecure in the family and consider themselves to be unable of changing the situation; they practically see themselves as the victims of an unwanted situation.

Affectional and interpersonal damages of addiction continue even after quitting and the tense relationship between the addicted parents and their children will go on. In this situation after quitting, a deep disconnection is formed between the children and their parents that are known as permanent insecurity in family relations. In these conditions, on the one hand, children still blame their addicted parents or parent of their regression in life and missing opportunities due to drug addiction and, on the other hand, the parents, especially the father, seek to recover their dominating position before addiction by relying upon their clean history and quitting drugs. In this stage, the instability in the father-child relationship continues in another form.

After quitting, many parents seek to recover and stabilize the supervising role in the family by focusing on their young children and severely controlling them because they are afraid that the addiction may come back to the family. A participant says, "He's really afraid. Sometimes they're early, sometimes they're late. Now, he wants everyone to be at home at 8 or 9 because when he came home late, he was after drugs. He thinks that now if four people gather around or they say that they have been awake all night, they must have been doing something. My son and my son-in-law smoke hubble bubble. If they ask him to buy tobacco, we'll have a fight at home. He's really afraid" (Wife of an addict, 45 years old).

\section{b) The phenomenon of identity instability in children}

The phenomenon of identity instability in children, happening due to the above-mentioned causal factors, describes a condition where the children in families with addicted parents do not have a self-knowledge and are doubtful in understanding their own identity. They later on experience complications when they encounter the society. Therefore, in this situation, the identity of the children of addicted parents is in an unbalanced state between the bitter reality of what there is and the imagination of what ought to be. This situation is called identity instability because the children try to adapt themselves to the status quo.

\section{c) The context for emergence of identity instability of children}

The phenomenon of children's identity instability was observed in the 40 participants during the research. This phenomenon was asserted by both the children of addicted parents and the children of parents who were quitting or had already quit. The severity of this phenomenon is a function of the history of addiction in the family. Accordingly, the rate of children's identity instability is related to the history of drug addiction in the family, both considering the years of addiction and the generational history of addiction. 


\section{d) Meddling factors effective on strategies}

Encountering the phenomenon of identity instability, considering their pride weakness that is rooted in their mind imbalance between reality and desired, referring to the sense of internal losses, and regarding the others' focus on their weaknesses that are based on their parents' addiction, children try to overcome the situation as they wish. Accordingly, children who have experience with addicted parents or parent are in a fight with their identity instability under the influence of constant tensions within themselves and in the society.

\section{e) Strategies to overcome the phenomenon of identity instability in children}

Children act in various ways in response to the phenomenon of identity instability and take up different strategies. These reactions are in fact wide-range strategies that seek to remove, confront, or recover from this phenomenon. These strategies are enacted in three forms of removing the problem, confrontational, and recovery strategies. Each of these is selected and executed according to the children's status. The most important strategies used by the children are:

The strategy of removing the problem: They hide their parents from the public, reject their parents' addiction in front of others, focus on other people's issues, and finally feel ashamed in their privacy. They try to temporarily pacify themselves by apparently removing the problem of addiction from their lives. In this situation, the children's first solution is to hide their addicted parents from the public. They try to do this by not accompanying their parents in public places and shield themselves against other people's judgments, especially their friends'. A participant says, "When we go somewhere and we want to talk about this (father's addiction), he says no. He doesn't like to go to the meeting now. He says he doesn't want to see anybody. His friends didn't know. But his father didn't look good even after quitting. He had the same thin face. He used to ask me to go another way so his friends don't see him" (Wife of an addict, 38 years old). In some cases, children try to point out the flaws of other people to assure them that their parents are no different than other parents.

Confrontational strategies: Aggressive behavior, continuous crying, and verbal and physical violence are some of the most important affectional strategies used by children after they fail in the first strategy. In this situation, children feel insecure due to internal weakness and conflicts and harassment by other people. They begin crying for the smallest things. Some children confront this loss and execute the strategy of aggressive behavior. A child says, "I don't care about honor. He could do it, he did it. He'll also pay for it. Our relatives have no right to talk about this. I'll kill them" (Child and wife of an addict, 38 years old). In many cases, children have had numerous fights with their parents.

Recovery strategies: Trying to financially support the family and accompanying the non-addicted parent to maintain the family by helping in living costs, working, and consulting are examples of this strategy. Under this, children try to help in living costs, work and consult the non-addicted parent to have a hand in managing the family's life. This sort of assistance constitutes a wide range of financial and nonfinancial cooperation that sometimes continue for a lifetime due to instability in the family. In fact, children are forced to work for even a low wage instead of going to school. This strategy will ultimately lead to a change of roles between parents and children. A participant says, "My older daughter could accept it. She went to work. Helped me. She went to work to help us. When the children worked together, they each brought 50 thousand tomans. They used to ask me not spend and waste the money" (Wife of an addict, 45 years old).

\section{f) Consequences of applying the strategies}

Applying each of the above strategies has consequences. Therefore, strategies like removing the problem and confrontation that naturally constitute confrontation or violence will have negative, aggressive consequences and peaceful strategies like recovery will bring about softer, more personal consequences.

As explained, the strategies of removing the problem and confrontation will have consequences such as expulsion from the society, self-orientation, and verbal and physical violence. One of the most important consequences of violent strategies is the sense of being expelled from the society. In this condition, children are constantly expelled from the friends' circles due to the other people's focus on the differences in their lives with others. A participant says, "I'm still suffering from the complex. It's happened to me at school to tell me about my father (that he was drug addict and dealer). I'm not lying when I say that I still don't talk with the girl next door (who told me that). I don't talk to any of them. (Addiction) hurt us very bad because of what people talked about. This affected my mind" (Child and wife of an addict, 38 years old). 
Children of addicted parents will continue to be self-oriented when their mental, spiritual griefs sustain. In this situation, children have no tolerance for resistance or dissent.

Due to the children's self-orientation and low tolerance that is because of their mental pains, they may also act violently in relation to their environment. In fact, the children are both agents and victims of verbal and physical violence. Ultimately, the children of addicted parents are victims of their parents' absolute ignorance. This irresponsibility ranges from providing the minimum material requirements to protecting the children's physical and sexual privacy. A participant who had witnessed his sister's harassment by other addicts says, "He brought a thousand of bad people, impolite people, home. They used to touch my sister under the blanket when she was sleeping" (Child of an addict, 10 years old).

Application of recovery strategy and, before that, the unstable affectional situation in the family, leads to the emergence of softer, more personal consequences. The first and foremost damage suffered by the child is the mental damages including depression, anxiety, obsession, and humiliation. These children, in addition to deprivation of life's basic facilities that happens due to the family's limited financial resources, suffer from another deprivation that is spiritual.

A wide range of issues contributes to this deprivation, such as witnessing parent's fights and conflicts and staying far away from them and living in welfare centers. Children, in this situation, suffer from psychological pressures caused by internal tensions and social affairs and feel impatient and fatigued after some fighting. They lose most of their energy due to mental unrest and are incapable of accompanying their friends because of communicational disabilities. They reach a complete isolation stage at this point. They stay away from groups and communities and live in isolation. This extensive isolation both takes place in family relations and social relations.

The pain of comparison is due to the understanding of the differences between addicted parents and other parents. This can lead to a constant conflict with family members and, ultimately, bring about individual consequences like a destroyed self-confidence.

\section{CONCLUSION}

There is no country in the world that is safe from the damages of drug addiction. Iran is no exception. Drugs have been used since a long time ago and today human beings are severely threatened by these substances that are added to conflicts such as environmental crisis, population growth, and nuclear issues. Drug addiction imposes unrecoverable damages and consequences on the family, especially the children. Drug addiction in the family has numerous psychological and affectional effects on the members and their quality of relationships. These mental damages are often manifested in the form of verbal violence, lying, aggressive, angry reactions, aggressiveness, and testiness. Therefore, families with addicted parents suffer from a very harsh abnormal, unstable situation.

The abnormal educational context in these families enables the children to tend to various misbehaviors, such as raping (raping the stepmother in one case), addiction, etc., because the effects of drug addiction are imposed since birth and impact the children's quality of life-based on the time of addiction of the parents in different stages of their lives.

The stress of hiding the father's addiction from friends becomes more serious when children go to school and increase their grief. In this sense, they witness a duality in father's behavior. On the one hand, the father is the symbol of a kind person and, on the other hand, his personality is the manifestation of a criminal. Children are always afraid of becoming an orphan. They are unsatisfied with their father because he cannot financially support the family and they are dependent on others. They are tired of other people's judgments (Najafi Asl, 2015: 70). Children do not benefit from father's supports and must compensate for this issue all by themselves.

Therefore, children in families with addicted parents suffer from identity instability due to an undesirable affectional status, improper behavioral models, and external pressures. In this sense, they are in an unbalanced situation between the undesirable status quo and the inexistent desirable situation. They have numerous doubts in choosing and consolidating their values and beliefs and will never have a stable definition for them. 


\section{BIBLIOGRAPHIC REFERENCES}

Aghabakhshi, H. (1996). "Family and addiction", SSQ.V 6(10). Pp.48-72.

Abadinsky, H. (2005). Sociology of Drugs, Mohammad Ali Zakaria (Translated), Tehran, Ayeneh Book.

Ahmadi, H. (2016). Sociology of deviations, Tehran, Samt publication.

Azkia, M, \& Imani Jajormi, H. (2011). Practical research methods: application of grounded theory, Tehran, Keyhan Publication.

Ghorbani E, et al. (2014). "Studying the effects of parents' addiction on children's tendency to addiction and abandoning home (case study of Uromia)", DCQ. V 6(23). Pp33-48.

Jazayeri, A. (2002). "Parents' addiction and child abuse", DAO. V 1(1). Pp 1-49.

Mahboubimanesh, H. (2003). "Men's addiction as a threat against women and family", WSS. V 22(0). Pp 67-90.

Malekpour M, et al. (2012). "Comparing different types of child abuse in addicted and non-addicted people", JSW. V 13(48). Pp229-245.

Mohammadifar, M. (2013). "Effects of life skills education on family functions in women with addicted husband", JARDA. V 4(16). Pp25-39.

Najafi Asl, Z (2015). "A pathological study of addiction in Tehrani families", Office of Research and Education at Iran Drug Control Headquarters.

Narimani, M (2014). "Studying the different aspects of quality of life in children with addicted parents", JRD. V 6(1). PP108-122.

Shafiei, M (2013). "Comparing the paintings of family and house-tree-human in the group of children with addicted and non-addicted parents", JARDA. V 7(27). PP137-148.

How to cite this article: Najafi Asl, Z., \& Haghi, S. (2020). Sociological Study of Identity Instability in Children of Parents with Drug Addiction. Religación. Revista De Ciencias Sociales Y Humanidades, 5(23), 111-117. Retrieved from http://revista. religacion.com/index.php/religacion/article/view/604

Submitted: 17 December 2019 Accepted: 15 March 2020 Published: 31 March 2020

Religación. Revistais de Ciencias Sociales y Humanidades is a peer-reviewed open access journal published by CICSH-AL Centro de Investigaciones en Ciencias Sociales y Humanidades desde América Latina |Religación| 